\title{
An update on current management of advanced renal cell cancer, biomarkers, and future directions
}

\author{
Wanqing Iris Zhi* and Jenny J. Kim \\ *Correspondence: wzhi1@jhmi.edu

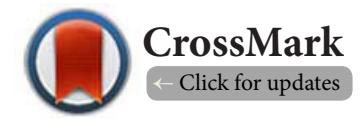

The Sidney Kimmel Cancer Comprehensive Center, Johns Hopkins Hospital, Baltimore, USA.

\begin{abstract}
In the past decade, metastatic renal cell carcinoma (mRCC) treatment underwent significant advancement that resulted in an unprecedented improvement in the prognosis of this disease. This review will provide an updated review of currently approved treatment options, namely antiangiogenic and immunotherapy, as well as treatment guideline recommended by the National Comprehensive Cancer Network (NCCN). We will summarize studies ongoing in determining prognostic and predictive biomarkers in maximizing therapeutic benefit in the treatment of this disease. Lastly, we will discuss promising agents in clinical testing.

Keywords: Renal cell carcinoma, target therapy, immunotherapy, tyrosine kinase inhibitor, monoclonal antibody, VEGF pathway, mTOR pathway, anti-PD-1 antibody, anti-CTLA-4 antibody, IL-2
\end{abstract}

\section{Introduction}

According to the American Cancer Society, there will be 63,920 newly diagnosed kidney cancer in the United States in 2014, and death of 13,860 people (8,900 men and 4,960 women) from this disease [1]. Kidney cancer is one of the top 10 cancers in both males and females and its overall prevalence has been steadily increasing since 1990s, mostly due to increased incidental detection of small renal masses as a result of increased use of non-invasive imaging studies. The death rate of kidney cancer has slightly decreased secondary to both early detection of the disease and the advancement in effective therapeutic measures discovered in the last decade [2]. However, metastatic disease at time of diagnosis steady rises with no definitive explanation and prognosis of metastatic disease ultimately remains quite poor.

In the past decade, the advent of targeted therapies has significantly improved metastatic renal cell carcinoma (mRCC) management. Anti-angiogenic agents targeting both vascular endothelial growth factor (VEGF) and mammalian target of Rapamycin (mTOR) pathways have been well studied and proven great efficacious in mRCC, mostly in clear cell carcinoma. Further, more recently, the reemergence of immunotherapy in the form of checkpoint inhibitors has shown very promising data, examples of which include cytotoxic T-lymphocyte associated antigen-4 (CTLA-4) and programmed death-1 (PD-1) receptor.
In this review, we provide an overview of systemic therapy for advanced kidney cancer with a focus on recent developments in targeted therapy and immunotherapy with available data, which demonstrated their benefits and adverse effects. We discuss about their indications in a front line setting as well as treating refractory disease. Furthermore, we provide updates on current research to identify predictive and prognostic biomarkers to guide selection of target therapies as well as ongoing investigations of new treatment strategies.

\section{Review \\ VEGF pathway targeted therapies Bevacizumab}

Bevacizumab is a VEGF receptor monoclonal antibody. Differently from small molecule tyrosine kinase inhibitors (TKI) targeting on VEGF pathway, it is a neutralizing antibody that binds VEGF ligand. It has been widely used in other types of solid tumor with varying results. Its utility as single and combination therapy in renal cell carcinoma has been well studied in AVOREN and other trials [3-6]. The AVOREN trial is a large multicenter, randomized trial compared efficacy between bevacizumab in combination with Interferon- $\alpha$ (IFN- $\alpha$ ) and IFN- $\alpha$ alone as a single therapy. Investigator assessed median progression free survival (PFS) is 10.2 months in bevacizumab with IFN- $\alpha$ Arm 
and 5.4 months in the IFN- $\alpha$ alone arm $(\mathrm{HR}=0.63, p<0.001)$. There was no statistically overall survival (OS) benefit in the bevacizumab arm possible due to the trial design allowing patient crossover to bevacizumab arm and patients from IFN- $\alpha$ group received more anticancer therapy poststudy [7]. The study shows that PFS at 3 months and 6 months are prognostic factors and currently it remains controversial whether PFS should be a surrogate primary end point rather than the OS. Based on AVOREN result, bevacizumab with IFN- $\alpha$ is considered as a first line therapy (Table 1). We will discuss IFN- $\alpha$ role in this regimen in the immunotherapy section below. Further, bevacizumab alone was well accepted for patients who failed TKI and cytokine therapy. Toxicities of bevacizumab are significant for hypertension, thromboembolism, myelosuppression and hemorrhage. These adverse effects are severe as grade 3-4 and limited bevacizumab uses in combination with TKI.

\section{Sunitinib}

FDA approved sunitinib as a first line therapy in mRCC in January 2006. It is a small tyrosine kinase inhibitor multi-targeting on VEGF receptor and platelet-derived growth factor receptor (PDGF-R) pathway. In a phase II trial, sunitinib demonstrates partial response rate (PRR) of $34 \%$ with a median PFS of 8.3 months in 105 patients with metastatic clear cell carcinoma failure previous therapy $[\mathbf{8 , 9}$. Master, R. J, et al., conducted a randomized phase III study comparing sunitinib with IFN- $\alpha$ in $675 \mathrm{mRCC}$ patients in the first line setting [8]. IFN- $\alpha$ was served as a first line therapy in mRCC at the time the study performed. It showed significantly longer median PFS of 11 months compared with IFN- $\alpha$ as 6 months. The objective response rate (ORR) was also significantly higher in the sunitinib group at $34 \%$ compared with IFN-aarm as $6 \%$. Based on this study, the FDA approved sunitinib as a first line therapy for mRCC. Long term follow up of 36 months in both groups revealed that sunitinib has median OS benefit 26.4 months versus IFN- $\alpha 21.8$ months $(p=0.051)$ [10]. Sunitinib toxicities include diarrhea, nausea, hypertension, hand-foot syndrome, cardio toxicity [11], and hypothyroidism, which is believed to relate to VEGF regulated thyroid atrophy and degeneration of thyroid follicular cells $[12,13]$. Several biomarkers for sunitinib therapy have been studied. For example, hypertension may serve as a predictive marker for sunitinib response $[\mathbf{1 4 , 1 5}]$. Circulating proteins and polymorphism of VEGF DNA have exhibited some predictive value $[16,17]$. Sunitinib in combination with IFN- $\alpha$, everolimus and bevacizumab have pronounced toxicity profile and has halted its development in combination therapy [18-20].

\section{Sorafenib}

Sorafenib is a multi-targeting tyrosine kinase inhibitor. Similar to sunitinib, it exhibits inhibitory activities against VEGF, PDGF-R, c-Kit, and c-MET. The TARGET trial is a phase III double blind, multicenter, randomized study in $900 \mathrm{mRCC}$ patients who failed prior chemotherapy and have lower or intermediate Memorial Sloan-Kettering Cancer Center (MSKCC) prognostic score [21]. The primary end point was investigator assessed PFS. In first 16 months of this study, sorafenib exhibited median PFS of 5.5 months compared with placebo for 2.8 months. The placebo group can crossover to sorafenib arm at 16 months and finally OS analysis revealed no significant difference between sorafenib and placebo groups $(p=0.145)$. The crossover design of the study there after understandably negated any survival difference at the end. However, the preplanned secondary analysis showed OS 17.8 months in the sorafenib group and 14.3 months in the placebo group ( $p=0.0287$ ).

Sorafenib was studied in the first line setting compared with IFN- $\alpha$ [22]. In this phase II trial, $400 \mathrm{mg}$ sorafenib oral twicedaily dose was compared with IFN- $\alpha 9$ million units (MU) three times weekly dose. In sorafenib group, the results showed 65 out of $97(67 \%)$ patient has progression disease, median PFS was 5.7 months and $5 \%$ objective response (complete and partial response). However, in IFN- $\alpha$ group, 56 out of 92 (60\%) patients had progression disease and a PFS of 5.6 months, resulting in early termination of the study. Currently, sorafenib is a secondline therapy in mRCC as per NCCN guideline based on above

Table 1. Summary of current therapies in mRCC.

\begin{tabular}{llll}
\hline & $\mathbf{1}^{\text {st }}$ Line & $\mathbf{2}^{\text {nd }}$ Line & Pipeline \\
\hline Multi targeting TKIs & $\begin{array}{l}\text { Sunitinib } \\
\text { Sorafenib } \\
\text { Pazopanib }\end{array}$ & $\begin{array}{l}\text { Axitinib } \\
\text { Sorafenib }\end{array}$ & $\begin{array}{l}\text { Cabozantinib (NCT01835158NCT01865747) } \\
\text { Dovitinib (NCT01223027) } \\
\end{array}$ \\
& & $\begin{array}{l}\text { Sunitinib } \\
\text { Pazopanib }\end{array}$ & $\begin{array}{l}\text { Lenvatinib (NCT01136733) } \\
--\end{array}$ \\
\hline VEGF receptor antibody & Bevacizumab with IFN-a & Bevacizumab & -- \\
\hline mTOR inhibitor & Temsirolimus & Everolimus & -- \\
& & Temsirolimus & -- \\
\hline Immunotherapy & HD-IL2 & HD-IL2 & Nivolumab (NCT01472081; NCT02210117) \\
& & & Ipilimumab (NCT00057889, NCT01472081) \\
& & & IMP321 (NCT00351949) \\
& & & AGS-003 (NCT01582672) \\
& & WX-G250 (NCT01826877) \\
\hline
\end{tabular}


data we just discussed.

\section{Pazopanib}

Pazopanib is a second generation TKI and was demonstrated in a phase III trial for local advanced RCC as adjuvant therapy post nephrectomy and second line setting in refractory RCC $[\mathbf{2 3}, \mathbf{2 4}]$. The open label phase III trial randomized pazopanib and placebo groups as 2:1 ratio with the option of crossover at time of progression. Total 435 patients were enrolled in this study, 290 were randomized to pazopanib group (half of whom had previous exposure to cytokine therapy) and 145 were in the matching placebo group. Overall PFS in the pazopanib group were 9.2 months and 4.2 months in the placebo group $(p<0.001)$. In a subset analysis, PFS in treatment naïve population showed a median PFS of 11.1 months and 2.8 months in the placebo group $(p<0.001)$. Among those who failed prior cytokine therapy, pazopanib group 135 patients had median PFS 7.4 months compared with placebo group 67 patients PFS 4.2 months $(p<0.01)$. ORR was $30 \%$ of the entire pazopanib cohort, $32 \%$ in treatment naïve population and $29 \%$ in cytokine refractory population. COMPARZ study compared efficacy of pazopanib versus sunitinib as a first line setting in the treatment of mRCC [25]. This study included advanced or metastatic RCC with clear cell history with no prior therapy. A total of 1110 patients was randomized as 1:1 ratio to pazopanib $800 \mathrm{mg}$ daily continuous dosing or sunitinib 50mg daily 4 weeks on and 2 weeks off dosing. The study allowed dose reduction in both groups. The primary endpoint in this study was PFS based on independent review. Upon 36 months of follow up, median PFS was 8.4 months in pazopanib group and 9.5 months in sunitinib group. Interim analysis of OS showed 28.4 and 29.3 months in pazopanib and sunitinib groups respectively $(p=0.275)$. However, the patient preferability (not adverse profile) profile is much more favorable for pazopanib as less severe bone marrow suppression, hypothyroidism, mucositis, fatigue and hand-foot syndrome. This study demonstrated pazopanib as a non-inferior agent to sunitinib in the first line setting with similar ORR and OS. Much lower incidence of adverse events in pazopanib group and better quality of life scores suggested that pazopanib might provide better quality of life during therapy than sunitinib with similar efficacy, however, the discontinuation rate in both pazopanib and sunitinib group are similar.

\section{Axitinib}

Another second generation TKI axitinib was studied in a phase III trial compared with sorafenib as second and first line therapy in treatment mRCC [26]. In the second line study, mRCC population focused on those who failed prior treatments included cytokine therapy, sunitinib, temsirolimus and bevacizumab treatment. The trial was randomized as 1:1 ratio based on patient performance status and type of prior of treatment to either axitinib $5 \mathrm{mg}$ twice daily or sorafenib $400 \mathrm{mg}$ twice daily. The primary endpoint was PFS by an independent review committee. Overall PFS in this study were 6.7 months for axitinib as compared with sorafenib arm about 4.7 months $(p<0.0001)$. In subgroup analysis by prior regimen, axitinib had better efficacy than sorafenib in patient population $(n=251)$ who failed prior cytokine therapy. There were 369 patients who received sunitinib in the past, 24 patients had temsirolimus and 59 patients who received bevacizumab before enrolling in the study. In patients previously treated with sunitinib, median PFS was 4.8 months in axitinib arm and 3.4 months in sorafenib $\operatorname{arm}(p=0.011)$. This suggested that axitinib could be used in the prior TKI refractory mRCC population. Further, adverse events in this trial demonstrated axitinib had a similar safety profile compared to sorafenib but more pronounced in hypertension, hypothyroidism and less hand-foot syndrome, rash and alopecia. Currently, axitinib is considered as a standard second line treatment of advanced RCC [27].

\section{Tivozanib}

Tivozanib is a third generation TKIs, which is a more potent biochemical inhibitor targeting of VEGF. TIVO-1 was the phase III superiority study of tivozanib compared with sorafenib as first line therapy in mRCC [28]. This study demonstrated tivozanib had superior efficacy compared with sorafenib as first line TKI therapy in advanced RCC. Tivozanib was well tolerated with less adverse events and toxicity,and fewer dose adjustments. Tivozanib was not approved, however, due to the similar OS seen in tivozanib (28.8 months) and sorafenib (29.3 months), with a non-significant hazard ratio of 1.25 (with a $95 \%$ confidence interval from 0.95-1.62). Another possible reason was the study, allowing patient crossover from sorafenib arm to tivozanib arm, but not in the other direction. This caused the question of equipoise of two arms.

\section{Cabozantinib}

Cabozantinib is a newly developed potent VEGF-2 and $c-M E T$ dual inhibitor. Recently, studies showed MET signaling is important for maintaining VEGF signaling in tumor angiogenesis, invasion, proliferation and survival [29]. It is also suggested that MET signaling might play a role in VEGF inhibitor resistance. 25 patients were enrolled in a phase $1 \mathrm{~B}$ trial of cabozantinib (XL184-008). In this trial, all patients had metastatic refractory RCC with an average of two previous treatments and intermediate to poor prognosis risks. In this study, 7 patients (28\%) achieved partial response with median PFS 14.7 months, 13 patients had stable disease and one had disease progression [30].

Currently, cabozantinib is being further investigated in a randomized phase II trial in comparison with sunitinib in previously untreated $\mathrm{mRCC}$ with intermediate and poor risks (NCT01835158). The primary objective is to study PFS and OS and the second objective is ORR and adverse events. This study is designed to allow patient crossover from sunitinib group to cabozantinib group upon the time of disease progression. A total of 140 patients will participate in this study and it is recruiting patients national wide. Need to point out: there is no prognostic biomarker available for treatment with MET inhibitors. 
Zhi et al. Journal of Cancer Therapeutics \& Research 2014,

\section{Dovitinib}

Dovitinib is a new TKIs targeting both VEGF and fibroblast growth factor receptor (FGFR) pathways. Preclinical studies have demonstrated this dual TKI also has activity against topoisomerase [31]. The phase 3 trial conducted by Motzer et, al has studied its efficacy compared with sorafenib in mRCC patients who progressed on previous VEGF or mTOR inhibitor therapies [32]. In this open label, randomized trial, a total of 284 were assigned to dovitinib group and 286 to sorafenib group. The median PFS was 3.7 and 3.6 months in dovitinib and sorafenib groups, respectively, showing no improvement in benefit over sorafenib in the third line setting.

\section{Lenvatinib}

Lenvatinib (E7080) has inhibition activity towards VEGF, FGFR, PDGFR, $c$-Kit and RET. It was studied in refractory thyroid cancer and hepatocellular carcinoma with very promising results. Phase III SELECT trial for refractory thyroid cancer reported in ASCO 2014 annual meeting (abstract LBA6008) showed substantial response in PFS: 18.3 versus 3.6 months in lenvatinib and the placebo group. Currently lenvatinib is under investigation in mRCC. Its safety and maximum toxicity dose are being evaluated in an early phase I/II trial alone or in combination with everolimus (NCT 01136733) [33].

\section{The mTOR inhibitors Temsirolimus}

Temsirolimus is a mTOR Inhibitor that has been shown to have activity in mRCC $[34,35]$. A phase III trial has studied temsirolimus as first line treatment of poor risk mRCC [36]. This was a randomized, international multi-centered trial, which enrolled total 620 patients with previously untreated mRCC. All patients were stratified as poor prognostic risk as three or more predictors of poor risks: LDH more than 1.5 times of upper normal limit, hemoglobin less than the lower normal limit, correct calcium more than $10 \mathrm{mg} / \mathrm{dl}$, time from diagnosis to first treatment less than one year, 60-70\% Karnofsky performance score and multi organ sites of metastasis. This study has included all histology types of RCC rather than most of TKI trials only include clear cell histology. The study was comprised of three arms: 1) IFN-a 3 MU three times weekly with escalating dose up to $18 \mathrm{MU}(\mathrm{n}=202) ; 2)$ temsirolimus $25 \mathrm{mg}$ intravenously weekly $(\mathrm{n}=209) ; 3$ ) combination of temsirolimus $15 \mathrm{mg}$ intravenous weekly with IFN-a 6 MU three times weekly $(n=210)$. The primary endpoint of this study was to compare OS in those three groups. Temsirolimus has median OS as 10.9 months, IFN- $\alpha$ median OS 7.3 months and combination of both as OS of 8.4 months. When compared Temsirolimus arm (2) with IFN-aarm (1), $p=0.008$, IFN- $\alpha$ arm (1) with combination arm (3), $p=0.70$. Poor prognostic risk and age less than 65 years old patients can benefit from temsirolimus more than an IFN- $\alpha$ group. The clear cell histology and other type of histology are favored temsirolimus. Intermediated prognostic risk and patients elder than 65 years old tend to benefit from IFN- $\alpha$. Adverse event of temsirolimus is most significant for rash, hyperlipidemia, hyperglycemia and stomatitis. It has less neutropenia, nausea and asthenia compared with IFN- $\alpha$ [37]. As a result of this study, temsirolimus has a category $1 \mathrm{~A}$ designation in the NCCN guideline choice for previously untreated mRCC patients with poor prognostic risks. In combination with bevacizumab as first line therapy for $\mathrm{mRCC}$ has not shown superior than IFN-a with bevacizumab in recently phase III clinical trial [38]. Recently data suggests when compared with sorafenib, temsirolimus has no benefit in improving PFS or OS as second line therapy after previous sunitinib [39]. Those studies suggest that VEGF target therapy and mTOR inhibitors sequential therapy might be important in mRCC treatment algorithm.

\section{Everolimus}

Everolimus is another potent mTOR inhibitor studied as second line therapy in the setting of progression after VEGF TKI therapy [40-42]. In this study [42], 410 patients with clear cell carcinoma who failed one or two previous VEGF target therapy were enrolled in the study. They were further stratified based on MSKCC risk score: $29 \%$ are high-risk group, 56\% are intermediate group and $15 \%$ are low risk group. They were randomized into two arms as 2:1 ratio. Arm 1 was everolimus with best supportive care $(n=272)$ and Arm 2 was placebo with best supportive care $(n=138)$ and the study allowed for the crossover from placebo to everolimus arm upon progression. Two interim analyses were conducted during the 13 months of study. The median PFS was studied by a central radiology review and results showed everolimus median PFS of 4 months for everolimus versus 1.9 months for placebo (Hazard ration $=0.30$, log-rank $p<0.01$ ). However, everolimus did show higher rates of adverse events: Grade 3 and 4 stomatitis, infections and pneumonitis. Other major side effects included asthenia, rash, nausea, vomiting, and mucosal inflammation. Based on this result, everolimus is recommended by the NCCN panel as second or third line therapy for renal cell carcinoma after prior VEGF TKI treatment [43].

\section{Immunotherapy \\ High dose of interleukin-2 (HD-IL2)}

Before 2005, cytokines were the only treatment options for metastatic renal cell carcinoma patients with modest benefits at best with the caveat that high dose of IL-2 does still remain as the only agent to achievedurable responses in $5-7 \%$ of patients. In a study of 255 patients, HD-IL2 had ORR of $14 \%$, with $5 \%$ of complete response [44]. Based on a follow up study, up to $20 \%$ patients lived more than 5 years after HD-IL2 treatment [45]. Recently another study showed HD-IL2 has median PFS of 4 months and $29 \%$ partial response rate in a total of 120 patients [46]. The challenge in the administration of HD-IL2 is significant side effects including hypotension, capillary leak syndrome and candidates should be carefully selected. A biomarker(s), which can predict response to IL2 would be of high benefit in selecting proper patients and therefore increasing therapeutic index. Those who can tolerate the treatment most likely have 
response to treatment with long duration [47]. The SELECT trial wasdesigned to attempt to identifya predictive model for patient selection for HD-IL2. The initial result showed 28\% ORR and clear cell histology appears to have better response. But further analysis of tumor and blood based predictive biomarker carbonic anhydrase IX (CAIX) are neither predictive nor prognostic.

\section{Interferon- $\alpha$}

In a large retrospective analysis, IFN- $\alpha$ as single therapy showed median OS as 13 months [48]. The result correlated well with MSKCC risk groups. The favorable group had median survival time of 30 months, intermediate group 14 months and poor risk groups with 5 months. Further meta-analysis study showed IFN- $\alpha$ with a very modest survival benefit [48]. IFN- $\alpha$ remained an effective option in highly selected patient populations and as a comparator in clinical trials of new therapy for the development of targeted therapies $[\mathbf{4 8 , 4 9}$. The Combination of IFN- $a$ with other agents like IL-2, however, did not demonstrate added efficacy $[\mathbf{5 0 , 5 1}]$. IFN- $\alpha$ in combination with bevacizumab was studying in the front line setting (discussed in the previous section) and is currently approved for use in this patient population.

\section{Checkpoint inhibitors}

Recently, the immune checkpoint pathway has been recognized to play an important regulatory role in antitumor immune response. Program death-1 (PD-1) and cytotoxic antigen 4 (CTLA-4) receptors, upon binding of their respective ligands, have negative regulatory function and therefore induce tumor immune escape [52]. Interfering this interaction with antibodies to the receptors are being studied as anti-tumor strategy by activating the immune system to induce $\mathrm{T}$ cell mediated antitumor effect and thereby leading to stunted antitumor response [53-55].

Program Death Receptor 1 (PD-1) is a member of CD 28 coreceptor family and it is expressed on naïve $T$ cells and activated $\mathrm{T}$ cells, B cells, natural killer cells in peripheral blood. PD-1 sustains expression on activated T cells and has two ligands, $\mathrm{PD}$ L1 and PD-L2. When PD-1 binds to its ligand during antigen recognition, it results in cross-linking of $\mathrm{PD}-1$ with antigen receptor complex. The PD-1 receptor is then phosphorylated, promoting SHP2 bound and inactivating ZAP70 in T cells and Syk in B cells [52]. The PD-1 activation induces inhibition of cell growth and cytokine secretion. It has been proven to be an important regulator in the process of immune response as well as peripheral immune tolerance [56]. In tumor cells, $\mathrm{PD}-1$ have been shown to increase expression level, less cytokine production and impaired cytotoxicity against tumor [54]. Blockade of the PD-1/PD-L1 pathway has been shown effective antitumor effects in early phase I/II studies $[\mathbf{5 7 , 5 8}]$.

\section{Nivolumab}

Nivolumab (BMS-936558/MDA-1106) is a fully human IgG4 anti PD-1 antibody. In a phase I study of nivolumab, one mRCC patient who failed multiple prior treatments achieved a partial response, which lasted about 16 months [59]. In a separate phase
I trial, among $34 \mathrm{mRCC}$ patients, 10 had objective responses to nivolumab, 9 additional patients had stable disease, which lasted about more than 16 weeks so far [60]. Those data indicated that anti PD-1 therapy could induce a durable response of antitumor effects similar to effects observed in HD-IL2 and IFN- $\alpha$ treatment in mRCC patients [61]. The major adverse effects are fatigue, rash, pruritus. Immune related adverse effects were also observed including vitiligo, pneumonitis, hepatitis, colitis, and thyroiditis [62]. Currently, there are more ongoing clinical trials to further elucidate the effectiveness of anti-PD-1 in mRCC patients. MultipleRCC clinical trialsare focused on efficacy of nivolumab in combination with everolimus, or VEGF tyrosine kinase inhibitors, or CTLA-4 antibody (NCT01472081; NCT01354431; NCT01668784). Results of a phase II CheckMate-010 trial that included three dose levels of single agent nivolumab in advanced mRCC were reported at ASCO 2014. There was 20\% ORR with duration of response up to 2 years [63]. Nivolumab in combination with VEGF tyrosine kinase inhibitor has been investigated in a phase I trial, and the current data confirm increased efficacy but also significantly increased toxicity. Further investigation of Anti-PD-1 in combination with TKIs is warranted with cautious monitoring adverse effects [64].

\section{Ipilimumab}

CTLA-4 is another important regulator in checkpoint pathway and has been explored as anti-tumor therapy [65]. It is a negative regulatory co-receptor expressed on inhibitory $\mathrm{T}$ cells with Foxp3 expression CD4+ T cells. CTLA-4 can bind to B7 ligand (CD 80 and CD 86) on antigen presenting cell and down regulate $\mathrm{CD} 28$ on effector T cells and suppresses diverse immune response. Foxp 3 cells express TGF- $\beta$, which is an important cytokine which promotes Foxp3 cell growth and differentiation. CTLA-4 is different from PD- 1 in checkpoint pathway: it regulates both cell intrinsic and extrinsic effects and has more systemic, non-antigen specific negative regulator in immune system $[\mathbf{6 6 , 6 7 ]}$. Further, CTLA-4 reduces production of IL-2, decreases the IL-2 receptor expression [68]. CTLA-4 antibody ipilimumab has been studied in a phase II trial of mRCC patients with previously HD-IL2 treatment [69]. There are 12 patients having an overall response to ipilimumab but adverse effects such as immune mediated hopo physitis and enteritis were reportedly much higher. One possible explanation is that inexperience with such an agent that erroneously pronounced severity in toxicity. Indeed, the combination of ipilimumab and nivolumab for treatment of mRCC has shown to exhibit unpresented success with manageable side effects. Recently data from Johns Hopkins Hospital was presented on ASCO 2014: a phase I/II CheckMate-016 combination of ipilimumab and nivolumab showed very tolerable toxicity profile. A phase III trial of the combination of ipilimumab and nivolumab is implementing based on above result [70].

\section{Future directions in immunotherapy}

Other important immune modulators are currently being 
explored for anti-tumor therapy. Lymphocyte-Activation Gene 3 (LAG-3) is a protein bind to MHC class II driven dendritic cell activation and promote effect $\mathrm{T}$ cell activation and antitumor activity. Recent in animal model, there is data suggesting immune an inhibitory synergistic effect between LAG-3 and PD-1 in promoting tumoral immune escape [71]. IMP321 is a recombinant soluble LAG-3 fusion protein, in a phase I trial, was investigated in $21 \mathrm{mRCC}$ patients with promising results [72]. Further investigation is needed for utility of IMP321 as a single agent or combination with other therapy, most interestingly, with anti PD-1 therapy. To date, Phase I study of IMP321 in mRCC is completed with the pending result; another ongoing phase I study of anti-PD1 with IMP321 is actively accrual (NCT00351949 and NCT01968109).

Immune therapy is also being explored in combination with other targeted therapies for mRCC patients. Other immune therapies include vaccine in combination with VEGF inhibitors are under investigation. So far, two vaccines have been tested in early phase clinical trials with promising results. IMA901 is a vaccine by selecting peptide associated with nine human leukocyte antigens (HLA) class I and one HLA class II binding peptides for tumor recognizing and activation of $\mathrm{T}$ cells. In a phase II study, 68 patients with refractory mRCC received IMA901 with GM-CSF and low dose of cyclophosphamide prior the first dose of vaccine. OS is $87 \%, 79 \%$ and $68 \%$ at 6 months, 12 months and 18 months [73]. Ongoing randomized phase III trial will further evaluate IMA901 as first line therapy in junction with Sunitinib (NCT01265901). Another newly developed vaccine is AGS-003. It is a dendritic cell based vaccine by fusing patient derived dendritic cells with autologous tumor. A phase II study showed 25 mRCC patients treated with AGS-003 with Sunitinib and have $62 \%$ clinical response and PFS of 12.5 months [74]. WX-G250 is an antibody binding to CAIX that regulate cell proliferation in response to hypoxia. In an early phase I/II trial, WX-G250 with low dose interferon was given to 25 patients post nephrectomy. The two-year survival was $57 \%$ and median overall survival was 30 months with minimal toxicity [75].

\section{Biomarkers}

In most mRCC clinical trials and studies, patient selections are purely based on eligibility criteria, including performance status, comorbidity and toxicity profiles. To date, no definitive biomarkers which would guide the careful selection of the proper population of mRCC patients for specific treatments. Especially for targeted therapy and immunotherapy, it is extremely important and urgent to identify predictive and prognostic biomarkers for maximizing therapeutic index.

To this end, multiple molecules in the signaling pathways involved in angiogenesis and also in the resistance pathway as predictive biomarkers for mRCC including von Hippel-Lindau (VHL) gene mutations, phosphatidylinositol 3-kinase (PI3K)/ mTOR pathway, mitogen-activated protein kinase (MAPK)/ extracellular signal-regulated kinas (ERK), Insulin like growth factor receptor (IGFR), Wnt and MET. Thus far, however, no definitive results have been shown, while some in need of prospective validation [76].

As stated previously, HD-IL2 has been shown highly effective in subset of mRCC population. Multiple studies have been done aiming to identify a predictive biomarker for selecting proper population [77]. CAIX was tested in a phase II trial (SELECT trail) however with negative result. CAIX also tested for patient received Sorafenib but it turned out to be neither predictive nor prognostic [78].

Clear cell renal carcinoma has been shown better outcomes with VEGF inhibitors than non clear cell histology. VHL inactivation has no association with better response to VEGF inhibitors, but loss of function mutation of VHL has higher responded. High level hypoxia induced factor-1 $\alpha$ provided to more sensitive to Sunitinib [79]. VEGF levels in both tumor tissue and plasma have been studied for correlation with prior and post VEGF inhibitor treatments. The results showed baseline VEGF plasma concentrations could serve as a prognostic predictor for patients receive Sunitinib [80]. Pazopanib was also found to associate with a decrease of VEGF plasma concentration. Similarly, tumor pS6 and pAKT may be promising predictive biomarkers for mTOR inhibitor Temsirolimus [81]. In RCC, over expression of PD-L1 has been shown correlation with poor prognosis $[\mathbf{8 2}, \mathbf{8 3}]$. PD-1 and PD-L1 as biomarker and prognostic factor in RCC have gained a lot of interests and under investigation (NCT01358721).

Early toxicity like hypertension and hand-foot syndrome appears to be pharmacodynamics biomarkers for VEGF inhibitors $[\mathbf{1 4}, \mathbf{1 5}, \mathbf{8 4}]$. Drug induced interstitial and hypercholesterolemia can be associated with better outcomes for mTOR inhibitors $[85,86]$. PET scan theoretically can be a utility for detecting response to $\mathrm{mTOR}$ inhibitor by decreasing glucose intake. In a small study, high baseline FDG uptake may serve as prognostic factor but fail to show any predictive value [87].

As above mentioned, biomarkers for mRCC have been heavily studied but to date, there is no an effective predictive model for mRCC patient. In clinic, physicians are facing the difficulty to choose the right therapy for the right patient and not able provides some prognostic information based on our current data. The need to develop a comprehensive molecular or genetic level assay is warranted.

\section{Conclusion}

In the past decade, the development of VEGF and mTOR inhibitors has dramatically changed the systemic therapy landscape for mRCC patients. Treatment landscape is again foreseen to undergo a dramatic revision in the near future with the current development of immune checkpoint inhibitors such as anti PD-1/PD-L1 antibodies. However, it is important to keep in mind that still most therapeutic agents provide palliative benefit. Future directions of mRCC research should focus on identifying predictive and prognostic biomarkers, determining optimal sequential and/or combination therapy in the hopes of increasing therapeutic index and increase rates of durable remissions. 


\section{Competing interests}

The authors declare that they have no competing interests.

\section{Authors' contributions}

W.I.Z is responsible for collecting data, and preparing the manuscript. J.K is responsible for concept discussion and revision of the manuscript.

\section{Publication history}

Received: 09 September 2014 Revised: 17 October 2014

Accepted: 10 November 2014 Published: 18 November 2014

\section{References}

1. Siegel, R., Ma, J., Zou, Z. and Jemal, A. (2014). Cancer statistics, 2014. CA Cancer J Clin, 64, 9-29.

2. Collaborators, U.S.B.o.D. (2013). The state of US health, 19902010: burden of diseases, injuries, and risk factors. JAMA, 310, 591-608.

3. Escudier, B., Pluzanska, A., Koralewski, P., Ravaud, A., Bracarda, S., Szczylik, C., Chevreau, C., Filipek, M., Melichar, B. and Bajetta, E., et al. (2007). Bevacizumab plus interferon alfa-2a for treatment of metastatic renal cell carcinoma: a randomised, double-blind phase III trial. Lancet, 370, 2103-11.

4. Rini, B. I., Halabi, S., Taylor, J., Small, E. J. and Schilsky, R. L. (2004). Cancer and Leukemia Group B 90206: A randomized phase III trial of interferon-alpha or interferon-alpha plus antivascular endothelial growth factor antibody (bevacizumab) in metastatic renal cell carcinoma. Clin Cancer Res, 10, 2584-6.

5. Yang, J. C., Haworth, L., Sherry, R. M., Hwu, P., Schwartzentruber, D. J., Topalian, S. L., Steinberg, S. M., Chen, H. X. and Rosenberg, S. A. (2003). A randomized trial of bevacizumab, an anti-vascular endothelial growth factor antibody, for metastatic renal cancer. $N$ Engl J Med, 349, 427-34.

6. Bukowski, R. M., Kabbinavar, F. F., Figlin, R. A., Flaherty, K., Srinivas, S., Vaishampayan, U., Drabkin, H. A., Dutcher, J., Ryba, S., Xia, Q., Scappaticci, F. A. and McDermott, D. (2007). Randomized phase II study of erlotinib combined with bevacizumab compared with bevacizumab alone in metastatic renal cell cancer. J Clin Oncol, 25, 4536-41.

7. Escudier, B., Bellmunt, J., Negrier, S., Bajetta, E., Melichar, B., Bracarda, S., Ravaud, A., Golding, S., Jethwa, S. and Sneller, V. (2010). Phase III trial of bevacizumab plus interferon alfa-2a in patients with metastatic renal cell carcinoma (AVOREN): final analysis of overall survival. J Clin Oncol, 28, 2144-50.

8. Motzer, R. J., Hutson, T. E., Tomczak, P., Michaelson, M. D., Bukowski, R. M., Rixe, O., Oudard, S., Negrier, S., Szczylik, C., Kim, S. T., Chen, I., Bycott, P. W., Baum, C. M. and Figlin, R. A. (2007). Sunitinib versus interferon alfa in metastatic renal-cell carcinoma. N Engl J Med, 356, 115-24.

9. Motzer, R. J., Rini, B. I., Bukowski, R. M., Curti, B. D., George, D. J., Hudes, G. R., Redman, B. G., Margolin, K. A., Merchan, J. R., Wilding, G., Ginsberg, M. S., Bacik, J., Kim, S. T., Baum, C. M. and Michaelson, M. D. (2006). Sunitinib in patients with metastatic renal cell carcinoma. JAMA, 295, 2516-24.

10. Motzer, R. J., Hutson, T. E., Tomczak, P., Michaelson, M. D., Bukowski, R. M., Oudard, S., Negrier, S., Szczylik, C., Pili, R. and Bjarnason, G. et al. (2009). Overall survival and updated results for sunitinib compared with interferon alfa in patients with metastatic renal cell carcinoma. J Clin Oncol, 27, 3584-90.

11.Schmidinger, M., Zielinski, C. C., Vogl, U. M., Bojic, A., Bojic, M., Schukro, C., Ruhsam, M., Hejna, M. and Schmidinger, H.
(2008). Cardiac toxicity of sunitinib and sorafenib in patients with metastatic renal cell carcinoma. J Clin Oncol, 26, 5204-12.

12. Rini, B. I., Tamaskar, I., Shaheen, P., Salas, R., Garcia, J., Wood, L., Reddy, S., Dreicer, R. and Bukowski, R. M. (2007). Hypothyroidism in patients with metastatic renal cell carcinoma treated with sunitinib. J Natl Cancer Inst, 99, 81-3.

13. Shinohara, N., Takahashi, M., Kamishima, T., Ikushima, H., Otsuka, N., Ishizu, A., Shimizu, C., Kanayama, H. and Nonomura, K. (2011). The incidence and mechanism of sunitinib-induced thyroid atrophy in patients with metastatic renal cell carcinoma. Br J Cancer, 104, 241-7.

14. Bono, P., Rautiola, J., Utriainen, T. and Joensuu, H. (2011). Hypertension as predictor of sunitinib treatment outcome in metastatic renal cell carcinoma. Acta Oncol, 50, 569-73.

15. Rini, B. I., Cohen, D. P., Lu, D. R., Chen, I., Hariharan, S., Gore, M. E., Figlin, R. A., Baum, M. S. and Motzer, R. J. (2011). Hypertension as a biomarker of efficacy in patients with metastatic renal cell carcinoma treated with sunitinib. J Natl Cancer Inst, 103, 763-73.

16. Deprimo, S. E., Bello, C. L., Smeraglia, J., Baum, C. M., Spinella, D., Rini, B. I., Michaelson, M. D. and Motzer, R. J. (2007). Circulating protein biomarkers of pharmacodynamic activity of sunitinib in patients with metastatic renal cell carcinoma: modulation of VEGF and VEGF-related proteins. J Transl Med, 5, 32.

17.Harmon, C. S., DePrimo, S. E., Figlin, R. A., Hudes, G. R., Hutson, T. E., Michaelson, M. D., Negrier, S., Kim, S. T., Huang, X., Williams, J. A., Eisen, T. and Motzer, R. J. (2014). Circulating proteins as potential biomarkers of sunitinib and interferon-alpha efficacy in treatment-naive patients with metastatic renal cell carcinoma. Cancer Chemother Pharmacol, 73, 151-61.

18. Motzer, R. J., Hudes, G., Wilding, G., Schwartz, L. H., Hariharan, S., Kempin, S., Fayyad, R. and Figlin, R. A. (2009). Phase I trial of sunitinib malate plus interferon-alpha for patients with metastatic renal cell carcinoma. Clin Genitourin Cancer, 7, 28-33.

19. Molina, A. M., Feldman, D. R., Voss, M. H., Ginsberg, M. S., Baum, M. S., Brocks, D. R., Fischer, P. M., Trinos, M. J., Patil, S. and Motzer, R. J. (2012). Phase 1 trial of everolimus plus sunitinib in patients with metastatic renal cell carcinoma. Cancer, 118, 1868-76.

20. Feldman, D. R., Baum, M. S., Ginsberg, M. S., Hassoun, H., Flombaum, C. D., Velasco, S., Fischer, P., Ronnen, E., Ishill, N., Patil, S. and Motzer, R. J. (2009). Phase I trial of bevacizumab plus escalated doses of sunitinib in patients with metastatic renal cell carcinoma. J Clin Oncol, 27, 1432-9.

21.Escudier, B., Eisen, T., Stadler, W. M., Szczylik, C., Oudard, S., Siebels, M., Negrier, S., Chevreau, C., Solska, E. and Desai, A. A., et al. (2007). Sorafenib in advanced clear-cell renal-cell carcinoma. N Engl J Med, 356, 125-34.

22.Escudier, B., Szczylik, C., Hutson, T. E., Demkow, T., Staehler, M., Rolland, F., Negrier, S., Laferriere, N., Scheuring, U. J., Cella, D., Shah, S. and Bukowski, R. M. (2009). Randomized phase II trial of first-line treatment with sorafenib versus interferon Alfa-2a in patients with metastatic renal cell carcinoma. J Clin Oncol, 27, 1280-9.

23.Sternberg, C. N., Davis, I. D., Mardiak, J., Szczylik, C., Lee, E., Wagstaff, J., Barrios, C. H., Salman, P., Gladkov, O. A. and Kavina, A., et al. (2010). Pazopanib in locally advanced or metastatic renal cell carcinoma: results of a randomized phase III trial. J Clin Oncol, 28, 1061-8.

24.Sternberg, C. N., Hawkins, R. E., Wagstaff, J., Salman, P., Mardiak, 
J., Barrios, C. H., Zarba, J. J., Gladkov, O. A., Lee, E., Szczylik, C., McCann, L., Rubin, S. D., Chen, M. and Davis, I. D. (2013). A randomised, double-blind phase III study of pazopanib in patients with advanced and/or metastatic renal cell carcinoma: final overall survival results and safety update. Eur J Cancer, 49, 1287-96.

25. Motzer, R. J., Hutson, T. E., Cella, D., Reeves, J., Hawkins, R., Guo, J., Nathan, P., Staehler, M., de Souza, P., Merchan, J. R. and Boleti, E., et al. (2013). Pazopanib versus sunitinib in metastatic renal-cell carcinoma. N Engl J Med, 369, 722-31.

26. Rini, B. I., Escudier, B., Tomczak, P., Kaprin, A., Szczylik, C., Hutson, T. E., Michaelson, M. D., Gorbunova, V. A., Gore, M. E., Rusakov, I. G. and Negrier, S., et al. (2011). Comparative effectiveness of axitinib versus sorafenib in advanced renal cell carcinoma (AXIS): a randomised phase 3 trial. Lancet, 378, 19319.

27.Hutson, T. E., Lesovoy, V., Al-Shukri, S., Stus, V. P., Lipatov, O. N., Bair, A. H., Rosbrook, B., Chen, C., Kim, S. and Vogelzang, N. J. (2013). Axitinib versus sorafenib as first-line therapy in patients with metastatic renal-cell carcinoma: a randomised open-label phase 3 trial. Lancet Oncol, 14, 1287-94.

28. Motzer, R. J., Nosov, D., Eisen, T., Bondarenko, I., Lesovoy, V., Lipatov, O., Tomczak, P., Lyulko, O., Alyasova, A. and Harza, M., et al. (2013). Tivozanib versus sorafenib as initial targeted therapy for patients with metastatic renal cell carcinoma: results from a phase III trial. J Clin Oncol, 31, 3791-9.

29. Yakes, F. M., Chen, J., Tan, J., Yamaguchi, K., Shi, Y., Yu, P., Qian, F., Chu, F., Bentzien, F., Cancilla, B., Orf, J., You, A., Laird, A. D., Engst, S., Lee, L., Lesch, J., Chou, Y. C. and Joly, A. H. (2011). Cabozantinib (XL184), a novel MET and VEGFR2 inhibitor, simultaneously suppresses metastasis, angiogenesis, and tumor growth. Mol Cancer Ther, 10, 2298-308.

30. Vaishampayan, U. (2013). Cabozantinib as a novel therapy for renal cell carcinoma. Curr Oncol Rep, 15, 76-82.

31.Hasinoff, B. B., Wu, X., Nitiss, J. L., Kanagasabai, R. and Yalowich, J. C. (2012). The anticancer multi-kinase inhibitor dovitinib also targets topoisomerase I and topoisomerase II. Biochem Pharmacol, 84, 1617-26.

32. Motzer, R. J., Porta, C., Vogelzang, N. J., Sternberg, C. N., Szczylik, C., Zolnierek, J., Kollmannsberger, C., Rha, S. Y., Bjarnason, G. A. and Melichar, B., et al. (2014). Dovitinib versus sorafenib for third-line targeted treatment of patients with metastatic renal cell carcinoma: an open-label, randomised phase 3 trial. Lancet Oncol, $15,286-96$

33. Molina, A. M., Hutson, T. E., Larkin, J., Gold, A. M., Wood, K., Carter, D., Motzer, R. and Michaelson, M. D. (2014). A phase $1 \mathrm{~b}$ clinical trial of the multi-targeted tyrosine kinase inhibitor lenvatinib (E7080) in combination with everolimus for treatment of metastatic renal cell carcinoma (RCC). Cancer Chemother Pharmacol, 73, 181-9.

34.Motzer, R. J., Hudes, G. R., Curti, B. D., McDermott, D. F., Escudier, B. J., Negrier, S., Duclos, B., Moore, L., O’Toole, T., Boni, J. P. and Dutcher, J. P. (2007). Phase I/II trial of temsirolimus combined with interferon alfa for advanced renal cell carcinoma. $J$ Clin Oncol, 25, 3958-64.

35. Mackenzie, M. J., Rini, B. I., Elson, P., Schwandt, A., Wood, L., Trinkhaus, M., Bjarnason, G. and Knox, J. (2011). Temsirolimus in VEGF-refractory metastatic renal cell carcinoma. Ann Oncol, $22,145-8$.

36. Hudes, G. et al. (2007). Temsirolimus, interferon alfa, or both for advanced renal-cell carcinoma. N Engl J Med, 356, 2271-81.

37. Bhojani, N., Jeldres, C., Patard, J. J., Perrotte, P., Suardi, N.,
Hutterer, G., Patenaude, F., Oudard, S. and Karakiewicz, P. I. (2008). Toxicities associated with the administration of sorafenib, sunitinib, and temsirolimus and their management in patients with metastatic renal cell carcinoma. Eur Urol, 53, 917-30.

38. Rini, B. I., Bellmunt, J., Clancy, J., Wang, K., Niethammer, A. G., Hariharan, S. and Escudier, B. (2014). Randomized phase III trial of temsirolimus and bevacizumab versus interferon alfa and bevacizumab in metastatic renal cell carcinoma: INTORACT trial. J Clin Oncol, 32, 752-9.

39. Hutson, T. E., Escudier, B., Esteban, E., Bjarnason, G. A., Lim, H. Y., Pittman, K. B., Senico, P., Niethammer, A., Lu, D. R., Hariharan, S. and Motzer, R. J. (2014). Randomized phase III trial of temsirolimus versus sorafenib as second-line therapy after sunitinib in patients with metastatic renal cell carcinoma. J Clin Oncol, 32, 760-7.

40. Motzer, R. J., Escudier, B., Oudard, S., Hutson, T. E., Porta, C., Bracarda, S., Grunwald, V., Thompson, J. A., Figlin, R. A., Hollaender, N., Kay, A. and Ravaud, A. (2010). Phase 3 trial of everolimus for metastatic renal cell carcinoma : final results and analysis of prognostic factors. Cancer, 116, 4256-65.

41. Molina, A. M., Ginsberg, M. S. and Motzer, R. J. (2011). Longterm response with everolimus for metastatic renal cell carcinoma refractory to sunitinib. Med Oncol, 28, 1527-9.

42. Motzer, R. J., Escudier, B., Oudard, S., Hutson, T. E., Porta, C., Bracarda, S., Grunwald, V., Thompson, J. A., Figlin, R. A., Hollaender, N., Urbanowitz, G., Berg, W. J., Kay, A., Lebwohl, D. and Ravaud, A. (2008). Efficacy of everolimus in advanced renal cell carcinoma: a double-blind, randomised, placebo-controlled phase III trial. Lancet, 372, 449-56.

43. Calvo, E., Escudier, B., Motzer, R. J., Oudard, S., Hutson, T. E., Porta, C., Bracarda, S., Grunwald, V., Thompson, J. A., Ravaud, A., Kim, D., Panneerselvam, A., Anak, O. and Figlin, R. A. (2012). Everolimus in metastatic renal cell carcinoma: Subgroup analysis of patients with 1 or 2 previous vascular endothelial growth factor receptor-tyrosine kinase inhibitor therapies enrolled in the phase III RECORD-1 study. Eur J Cancer, 48, 333-9.

44. Fyfe, G., Fisher, R. I., Rosenberg, S. A., Sznol, M., Parkinson, D. R. and Louie, A. C. (1995). Results of treatment of 255 patients with metastatic renal cell carcinoma who received high-dose recombinant interleukin-2 therapy. J Clin Oncol, 13, 688-96.

45. Fyfe, G. A., Fisher, R. I., Rosenberg, S. A., Sznol, M., Parkinson, D. R. and Louie, A. C. (1996). Long-term response data for 255 patients with metastatic renal cell carcinoma treated with highdose recombinant interleukin-2 therapy. J Clin Oncol, 14, 2410-1.

46. Clement, J. M. and McDermott, D. F. (2009). The high-dose aldesleukin (IL-2) "select" trial: a trial designed to prospectively validate predictive models of response to high-dose IL-2 treatment in patients with metastatic renal cell carcinoma. Clin Genitourin Cancer, 7, E7-9.

47. Fisher, R. I., Rosenberg, S. A. and Fyfe, G. (2000). Long-term survival update for high-dose recombinant interleukin-2 in patients with renal cell carcinoma. Cancer J Sci Am, 6 Suppl 1, S55-7.

48. Motzer, R. J., Bacik, J., Murphy, B. A., Russo, P. and Mazumdar, M. (2002). Interferon-alfa as a comparative treatment for clinical trials of new therapies against advanced renal cell carcinoma. $J$ Clin Oncol, 20, 289-96.

49. Flanigan, R. C., Salmon, S. E., Blumenstein, B. A., Bearman, S. I., Roy, V., McGrath, P. C., Caton, J. R., Jr., Munshi, N. and Crawford, E. D. (2001). Nephrectomy followed by interferon alfa-2b compared with interferon alfa- $2 \mathrm{~b}$ alone for metastatic renal-cell 
cancer. N Engl J Med, 345, 1655-9.

50.Negrier, S., Escudier, B., Lasset, C., Douillard, J. Y., Savary, J., Chevreau, C., Ravaud, A., Mercatello, A., Peny, J., Mousseau, M., Philip, T. and Tursz, T. (1998). Recombinant human interleukin-2, recombinant human interferon alfa-2a, or both in metastatic renal-cell carcinoma. Groupe Francais d'Immunotherapie. N Engl J Med, 338, 1272-8.

51.Atzpodien, J., Kirchner, H., Illiger, H. J., Metzner, B., Ukena, D., Schott, H., Funke, P. J., Gramatzki, M., Jurgenson, S., Wandert, T., Patzelt, T. and Reitz, M. (2001). IL-2 in combination with IFN- alpha and 5-FU versus tamoxifen in metastatic renal cell carcinoma: long-term results of a controlled randomized clinical trial. Br J Cancer, 85, 1130-6.

52.Parry, R. V., Chemnitz, J. M., Frauwirth, K. A., Lanfranco, A. R., Braunstein, I., Kobayashi, S. V., Linsley, P. S., Thompson, C. B. and Riley, J. L. (2005). CTLA-4 and PD-1 receptors inhibit T-cell activation by distinct mechanisms. Mol Cell Biol, 25, 9543-53.

53. Quezada, S. A. and Peggs, K. S. (2013). Exploiting CTLA-4, PD-1 and PD-L1 to reactivate the host immune response against cancer. Br J Cancer, 108, 1560-5.

54. Weber, J. (2010). Immune checkpoint proteins: a new therapeutic paradigm for cancer--preclinical background: CTLA-4 and PD-1 blockade. Semin Oncol, 37, 430-9.

55. Curran, M. A., Montalvo, W., Yagita, H. and Allison, J. P. (2010). PD- 1 and CTLA- 4 combination blockade expands infiltrating $\mathrm{T}$ cells and reduces regulatory $\mathrm{T}$ and myeloid cells within B16 melanoma tumors. Proc Natl Acad Sci U S A, 107, 4275-80.

56. Fife, B. T. and Bluestone, J. A. (2008). Control of peripheral T-cell tolerance and autoimmunity via the CTLA- 4 and PD- 1 pathways. Immunol Rev, 224, 166-82.

57. Callahan, M. K. and Wolchok, J. D. (2013). At the bedside: CTLA4- and PD-1-blocking antibodies in cancer immunotherapy. $J$ Leukoc Biol, 94, 41-53.

58. Intlekofer, A. M. and Thompson, C. B. (2013). At the bench: preclinical rationale for CTLA-4 and PD-1 blockade as cancer immunotherapy. J Leukoc Biol, 94, 25-39.

59. Brahmer, J. R., Tykodi, S. S., Chow, L. Q., Hwu, W. J., Topalian, S. L., Hwu, P., Drake, C. G., Camacho, L. H., Kauh, J., Odunsi, K., Pitot, H. C. and Hamid, O., et al. (2012). Safety and activity of anti-PD-L1 antibody in patients with advanced cancer. $N$ Engl $J$ Med, 366, 2455-65.

60. Topalian, S. L., Hodi, F. S., Brahmer, J. R., Gettinger, S. N., Smith, D. C., McDermott, D. F., Powderly, J. D., Carvajal, R. D., Sosman, J. A. and Atkins, M. B., et al. (2012). Safety, activity, and immune correlates of anti-PD-1 antibody in cancer. N Engl J Med, 366, 2443-54.

61.Lipson, E. J., Sharfman, W. H., Drake, C. G., Wollner, I., Taube, J. M., Anders, R. A., Xu, H., Yao, S., Pons, A., Chen, L., Pardoll, D. M., Brahmer, J. R. and Topalian, S. L. (2013). Durable cancer regression off-treatment and effective reinduction therapy with an anti-PD-1 antibody. Clin Cancer Res, 19, 462-8.

62. O'Sullivan Coyne, G., Madan, R. A. and Gulley, J. L. (2014). Nivolumab: promising survival signal coupled with limited toxicity raises expectations. J Clin Oncol, 32, 986-8.

63. Motzer, RJ., Rini, BI. And McDermott DF, et al. (2014). Nivolumab for metastatic renal cell carcinoma: Results of a randomized, dose-ranging phase II trial. ASCO Annual Meeting. Abstract 5009. 2014.

64. Amin, A., Plimack, ER. And Infante, JR., et al. (2014). Nivolumab
(anti-PD-1; BMS-936558, ONO-4538) in combination with sunitinib or pazopanib in patients with metastatic renal cell carcinoma. ASCO Annual Meeting. 2014.

65.Hodi, F. S., O’Day, S. J., McDermott, D. F., Weber, R. W., Sosman, J. A., Haanen, J. B., Gonzalez, R., Robert, C., Schadendorf, D., Hassel, J. C. and Akerley, W., et al. (2010). Improved survival with ipilimumab in patients with metastatic melanoma. N Engl J Med, $363,711-23$.

66. Walker, L. S. (2013). Treg and CTLA-4: two intertwining pathways to immune tolerance. J Autoimmun, 45, 49-57.

67. Bour-Jordan, H., Esensten, J. H., Martinez-Llordella, M., Penaranda, C., Stumpf, M. and Bluestone, J. A. (2011). Intrinsic and extrinsic control of peripheral T-cell tolerance by costimulatory molecules of the CD28/ B7 family. Immunol Rev, 241, 180-205.

68. Chikuma, S., Terawaki, S., Hayashi, T., Nabeshima, R., Yoshida, T., Shibayama, S., Okazaki, T. and Honjo, T. (2009). PD-1-mediated suppression of IL-2 production induces CD8+ T cell anergy in vivo. J Immunol, 182, 6682-9.

69. Yang, J. C., Hughes, M., Kammula, U., Royal, R., Sherry, R. M., Topalian, S. L., Suri, K. B., Levy, C., Allen, T., Mavroukakis, S., Lowy, I., White, D. E. and Rosenberg, S. A. (2007). Ipilimumab (anti-CTLA4 antibody) causes regression of metastatic renal cell cancer associated with enteritis and hypophysitis. J Immunother, $30,825-30$

70.Hammers, HJ., Plimack, ER. And Infante, JR., et al. (2014). Phase I study of nivolumab in combination with ipilimumab in metastatic renal cell carcinoma. ASCO Annual Meeting. 2014.

71. Woo, S. R., Turnis, M. E., Goldberg, M. V., Bankoti, J., Selby, M., Nirschl, C. J., Bettini, M. L., Gravano, D. M., Vogel, P., Liu, C. L. and Tangsombatvisit, S., et al. (2012). Immune inhibitory molecules LAG-3 and PD-1 synergistically regulate T-cell function to promote tumoral immune escape. Cancer Res, 72, 917-27.

72.Brignone, C., Escudier, B., Grygar, C., Marcu, M. and Triebel, F. (2009). A phase I pharmacokinetic and biological correlative study of IMP321, a novel MHC class II agonist, in patients with advanced renal cell carcinoma. Clin Cancer Res, 15, 6225-31.

73.C. Reinhardt, R.Z., C. Szczylik, T. Ciuleanu, W. Brugger, R. Oberneder, A. Kirner, S. Walter, H. Singh. And A. Stenzl, (2010). Results of a randomized phase II study investigating multipeptide vaccination with IMA901 in advanced renal cell carcinoma (RCC). in 2010 ASCO Annual Meeting. J Clin Oncol 28:15s.

74. D. Healey, A.H.G., A. Amin, V. Cohen and T. Logan, C. A. Nicolette. (2010). Immunomonitoring of a phase I/II study of AGS-003, a dendritic cell immunotherapeutic, as first-line treatment for metastatic renal cell carcinoma., in 2010 ASCO Annual Meeting. J Clin Oncol, 28.

75. Siebels, M., Rohrmann, K., Oberneder, R., Stahler, M., Haseke, N., Beck, J., Hofmann, R., Kindler, M., Kloepfer, P. and Stief, C. (2011). A clinical phase I/II trial with the monoclonal antibody cG250 (RENCAREX(R)) and interferon-alpha-2a in metastatic renal cell carcinoma patients. World J Urol, 29, 121-6.

76. Amato, R. J., Flaherty, A., Zhang, Y., Ouyang, F. and Mohlere, V. (2014). Clinical prognostic factors associated with outcome in patients with renal cell cancer with prior tyrosine kinase inhibitors or immunotherapy treated with everolimus. Urol Oncol, $32,345-54$

77. Atkins, M. B. (2009). Treatment selection for patients with metastatic renal cell carcinoma: identification of features favoring 
Zhi et al. Journal of Cancer Therapeutics \& Research 2014,

upfront IL-2-based immunotherapy. Med Oncol, 26 Suppl 1, 18-22.

78. Angela, Q., Qu, S.C., Michael, B., Atkins, Sabina Signoretti, Toni, K. (2012). Choueiri, Carbonic anhydrase IX (CAIX) as a potential biomarker of efficacy in metastatic clear-cell renal cell carcinoma (mccRCC) in patients (pts) receiving sorafenib: Analysis of a randomized controlled trial (TARGET). in 2012 Genitourinary Cancers Symposium. J Clin Oncol, 30.

79. Choueiri, T. K., Fay, A. P., Gagnon, R., Lin, Y., Bahamon, B., Brown, V., Rosenberg, J. E., Hutson, T. E., Baker-Neblett, K. L., Carpenter, C., Liu, Y., Pandite, L. and Signoretti, S. (2013). The role of aberrant VHL/HIF pathway elements in predicting clinical outcome to pazopanib therapy in patients with metastatic clearcell renal cell carcinoma. Clin Cancer Res, 19, 5218-26.

80.Bamias, A., Tzannis, K., Beuselinck, B., Oudard, S., Escudier, B., Diosynopoulos, D., Papazisis, K., Lang, H., Wolter, P. and de Guillebon, E., et al. (2013). Development and validation of a prognostic model in patients with metastatic renal cell carcinoma treated with sunitinib: a European collaboration. Br J Cancer, 109, 332-41.

81.Cho, D., Signoretti, S., Dabora, S., Regan, M., Seeley, A., Mariotti, M., Youmans, A., Polivy, A., Mandato, L., McDermott, D., Stanbridge, E. and Atkins, M. (2007). Potential histologic and molecular predictors of response to temsirolimus in patients with advanced renal cell carcinoma. Clin Genitourin Cancer, 5, 379-85.

82. Thompson, R. H., Dong, H., Lohse, C. M., Leibovich, B. C., Blute, M. L., Cheville, J. C. and Kwon, E. D. (2007). PD-1 is expressed by tumor-infiltrating immune cells and is associated with poor outcome for patients with renal cell carcinoma. Clin Cancer Res, 13, 1757-61.

83. Thompson, R. H., Gillett, M. D., Cheville, J. C., Lohse, C. M., Dong, H., Webster, W. S., Krejci, K. G., Lobo, J. R., Sengupta, S., Chen, L., Zincke, H., Blute, M. L., Strome, S. E., Leibovich, B. C. and Kwon, E. D. (2004). Costimulatory B7-H1 in renal cell carcinoma patients: Indicator of tumor aggressiveness and potential therapeutic target. Proc Natl Acad Sci U S A, 101, 171749.

84. Rini, B.I., et al., (2014). Hypertension among patients with renal cell carcinoma receiving axitinib or sorafenib: analysis from the randomized phase III AXIS trial. Target Oncol.

85.D. A. Dabydeen, J.P.J., N. H. Ramaiya, K. M. Krajewski, F. A. B. Schutz, D. C. Cho and I. Pedrosa, T. K. (2011). Choueiri, Pneumonitis associated with mTOR therapy in patients with metastatic renal cell carcinoma: Incidence, radiographic findings, and correlation with clinical outcome. ASCO Annual Meeting.

86. White, D. A., Camus, P., Endo, M., Escudier, B., Calvo, E., Akaza, H., Uemura, H., Kpamegan, E., Kay, A., Robson, M., Ravaud, A. and Motzer, R. J. (2010). Noninfectious pneumonitis after everolimus therapy for advanced renal cell carcinoma. Am J Respir Crit Care Med, 182, 396-403.

87.Chen, J. L., Appelbaum, D. E., Kocherginsky, M., Cowey, C. L., Rathmell, W. K., McDermott, D. F. and Stadler, W. M. (2013). FDG-PET as a predictive biomarker for therapy with everolimus in metastatic renal cell cancer. Cancer Med, 2, 545-52.

\section{Citation:}

Zhi WI and Kim JJ. An update on current management of advanced renal cell cancer, biomarkers, and future directions. J Cancer Ther Res. 2014; 3:8. http://dx.doi.org/10.7243/2049-7962-3-8 